\title{
A study to assess the knowledge regarding cardiopulmonary resuscitation (CPR) among Ist Year GNM (diploma nursing students) students studying in SND college of nursing with a view to develop an information booklet
}

\begin{abstract}
The cardiopulmonary resuscitation (CPR) guidelines of compression-only life support (COLS) for management of the victim with cardiopulmonary arrest in adults provide a stepwise algorithmic approach for optimal outcome of the victim outside the hospital by untrained laypersons. "A study to assess the knowledge regarding Cardiopulmonary resuscitation(CPR) among $1^{\text {st }}$ Year GNM (diploma nursing students) students studying in SND College of nursing with a view to develop an information booklet". Objectives are to assess the knowledge regarding CPR among $1^{\text {st }}$ Year GNM students. To find out the association between knowledge scores with their selected demographic variables $\&$ to prepare an information booklet. 50 samples were included in the study who all are fits in inclusive criteria, this is a descriptive design and analysis were done by using inferential statistics. The finding clearly shows that there is no one student had poor knowledge regarding CPR among the $1^{\text {st }}$ year RGNM students. There is $38 \%$ of adequate knowledge regarding CPR and the majority of $62 \%$ students having good knowledge about cardiopulmonary resuscitation (CPR). No one students of diploma nursing (GNM) belongs to nil knowledge regarding CPR. The study concludes that the GNM students required more knowledge and skill regarding CPR to practice effectively to save life of a victim. Even though majority of the GNM (diploma nursing students) had good knowledge but still perfection is required to practice it whenever needed in emergency.
\end{abstract}

Keywords: CPR, GNM (diploma nursing students) students, AHA and knowledge
Volume 5 Issue 5 - 2018

\section{Vijayaraddi Vandali, Akash Gujar, Urmila Kachare, Nikita Kapadne, Vanita Nagare, Lalita Raut, Wankar Padvi}

Department of Nursing, SND College of Nursing, Yeola, Maharashtra, India

Correspondence: Vijayaraddi Vandali, SND College of Nursing, Yeola, Maharashtra, India, Email vijay.snbcon@gmail.com

Received: May 28, 2018 | Published: October 09, 2018

\section{Introduction}

Cardiopulmonary resuscitation is a lifesaving technique for victims of sudden cardiac arrest. Despite advances in resuscitation science, basic life support remains a critical factor in determining outcomes. The American Heart Association recommendations for adult basic life support incorporate the most recently published evidence and serve as the basis for education and training for laypeople and healthcare providers who perform cardiopulmonary resuscitation. The cardiopulmonary resuscitation (CPR) guidelines of compression-only life support (COLS) for management of the victim with cardiopulmonary arrest in adults provide a stepwise algorithmic approach for optimal outcome of the victim outside the hospital by untrained laypersons. These guidelines have been developed to recommend practical, uniform and acceptable resuscitation algorithms across India. As resuscitation data of the Indian population are inadequate, these guidelines have been based on international literature. The guidelines have been recommended after discussion among Indian experts and the recommendations modified to ensure its practical applicability across the country. ${ }^{1}$

\section{Need for study}

According to statistics nearly 7.5 lakh people die of sudden cardiac arrests every year in India. On an average, a victim begins to suffer irreversible brain damage four minutes after the cardiac arrest takes place and if no CPR administered. ${ }^{2}$ For every minute that a cardiac arrest victim does not receive CPR, his chances of survival drops by 10 per cent. An effective CPR from a bystander can double a victim's chances of surviving a cardiac arrest. While several countries across the world are training the common man - in schools, colleges and work places about chest compressions or CPR to save sudden cardiac victims from dying, the World Heart Federation (WHF) says less than one per cent Indians would presently know how to carry out a CPR. ${ }^{3-5}$

\section{Review of literature}

A study was conducted by Prafulla A.Salunkhe to explore the Effectiveness of Demonstration Regarding Cardiopulmonary Resuscitation on Knowledge and Practice among Policemen, Quantitative research approach and one group pre-test and post-test design was used Non-probability convenient sampling method was used to select 50 policemen as a study subjects. .Conclusion- equal positive response to the demonstration and teaching was found really useful to them, which will help them to take prompt decisions, perform cardiopulmonary resuscitation and save many lives of out-ofhospitals cardiac arrest victims. ${ }^{6-10}$ 


\section{Statement of the problem}

A study to assess the knowledge regarding Cardiopulmonary resuscitation(CPR) among $1^{\text {st }}$ Year GNM students studying in SND College of nursing with a view to develop an information booklet.

\section{Objectives}

i. $\quad$ To assess the knowledge regarding CPR among $1^{\text {st }}$ Year GNM students.

ii. To find out the association between knowledge scores with their selected demographic variables.

iii. To prepare an information booklet.

\section{Operational definition}

\section{Knowledge}

In this study it refers to understanding the knowledge of the $1^{\text {st }}$ year RGNM students regarding cardiopulmonary resuscitation.

\section{Cardiopulmonary resuscitation}

Cardiopulmonary resuscitation (CPR) is a procedure to support and maintain breathing and circulation for and infant, child, and adolescent who has stop breathing (Respiratory arrest) and /or whose heart has stopped (Cardiac Arrest)

cardiopulmonary resuscitation is a emergency procedure that combines chest compression often with artificial ventilation in an effort to manually preserve intact brain function until further measures are taken to restore spontaneous blood circulation and breathing in a person who is in cardiac arrest. ${ }^{11-13}$

\section{Assumptions}

i. $\quad 1^{\text {st }}$ Year GNM students regarding CPR may have adequate knowledge regarding kangaroo mother care

ii. The knowledge regarding CPR among $1^{\text {st }}$ Year GNM students may be influenced by their selected Demographic variables. ${ }^{14-16}$

\section{Variables}

i. Independent variables: Information booklet on cardiopulmonary Resuscitation.

ii. Dependent variables: Knowledge

iii. Demographic variables: Age, Gender, Educational status, attain any CNE, Religious.

\section{Hypothesis}

H1: There is a significant association between the selected demographic variables and knowledge score of $1^{\text {st }}$ Year RGNM students.

H2: - There will be no relationship between demographic variables and Knowledge on CPR among RGNM students.

\section{Delimitations}

i. The study is delimited to GNM students ii. Students studying in only SND college of nursing

iii. The study is delimited to $1^{\text {st }}$ Year GNM students.

iv. The study is delimited to 50 samples.

\section{Material and methods}

Methodology of research indicates the general pattern of organizing the procedure for gathering valid and reliable data for problems under investigation.

\section{Source of data}

The data will be collected from $1^{\text {st }}$ year RGNM student in S.N.D College of Nursing at Yeola.

\section{Research design}

Descriptive Design.

\section{Research approach}

To assess the knowledge regarding CPR among the $1^{\text {st }}$ year RGNM students.

\section{Setting}

The study will be conducted in $1^{\text {st }}$ year RGNM students.

\section{Population}

The population for the study comprises of $1^{\text {st }}$ year RGNM student in Yeola.

\section{Methods of data collection}

\section{Sampling procedure}

$1^{\text {st }}$ year RGNM student will be selected by using convenient sampling technique.

\section{Sampling size}

The sample for the study would consist of 50 in $1^{\text {st }}$ year RGNM student.

\section{Inclusive criteria}

Both male and female included in this study,

i. The $1^{\text {st }}$ year RGNM students can able to read and write English.

ii. The $1^{\text {st }}$ year RGNM students who are present during the time of study.

iii. The $1^{\text {st }}$ year RGNM student who are willing the participate.

\section{Exclusive criteria}

i. The students are not willing to participant at study period.

ii. The students who are not present during the time of study.

\section{Instruments intended to be used}

a) Structured knowledge questionnaire.

b) Information booklet for giving education about Cardiopulmonary Resuscitation (CPR). 


\section{The findings were presented under the following headline}

The above table reveals that out of 50 , the age group 21 to 25 undergone the 45 (Table 1) students, about $90 \%$ percentages. In the age group 25 to 30 the frequency is 5 and the percentage is 10 . In the age group 30 and above about $0 \%$. Graphs $1-4$

Table I Frequency\& percentage distribution of $\left.\right|^{\text {st }}$ year RGNM student according to the age

\begin{tabular}{|c|c|c|}
\hline Age & Frequency & Parentage \\
\hline $21-25$ & 45 & 90 \\
\hline $25-30$ & 5 & 10 \\
\hline 30 \& Above & 0 & 0 \\
\hline Total & 50 & 100 \\
\hline Gender & Frequency & Percentage \\
\hline Male & 17 & 34 \\
\hline Female & 33 & 66 \\
\hline Total & 50 & 100 \\
\hline Educational qualification & Frequency & Percentage \\
\hline Science & 45 & 90 \\
\hline Commers & 0 & 0 \\
\hline Arts & 5 & 10 \\
\hline Mcve & 0 & 0 \\
\hline Total & 50 & 100 \\
\hline Religion & Frequency & PERSENTAGE \\
\hline Hindu & 50 & 100 \\
\hline Muslim & 0 & 0 \\
\hline Christian & 0 & 0 \\
\hline Other & 0 & 0 \\
\hline Total & 50 & 100 \\
\hline CNE Participation & Frequency & Percentage \\
\hline YES & 0 & 0 \\
\hline NO & 50 & 100 \\
\hline TOTAL & 50 & 100 \\
\hline
\end{tabular}

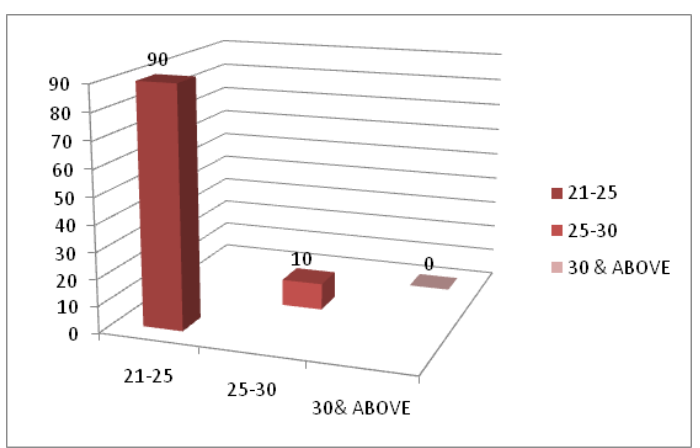

Graph I According to the frequency and percentage of age.

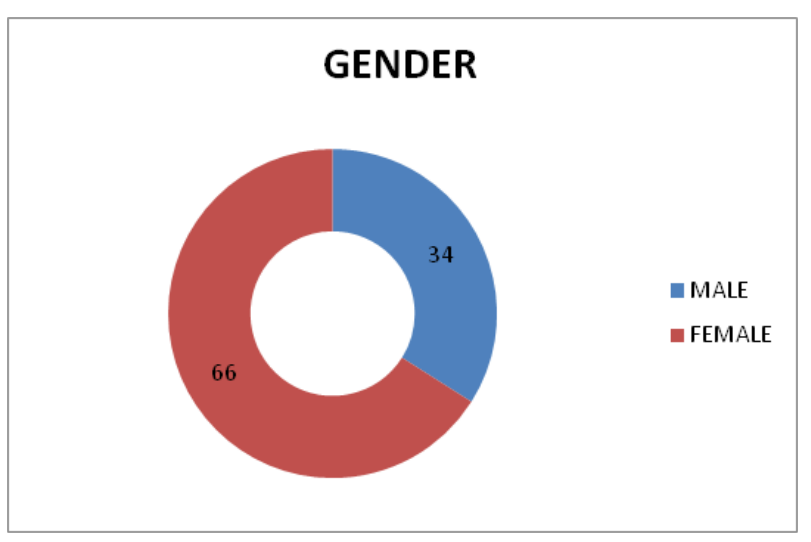

Graph 2 According to the frequency and percentage of gender.

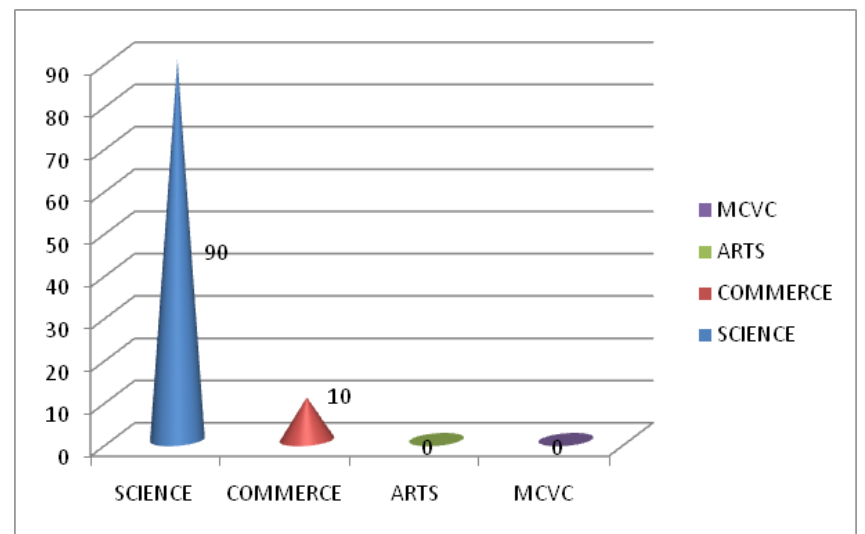

Graph 3 The above table revels that majority of the respondents $50(100 \%)$ were $\mathrm{Hindu}, 0(0 \%)$ were Muslim, $0(0 \%)$ were Christian, $0(0 \%)$ were other.

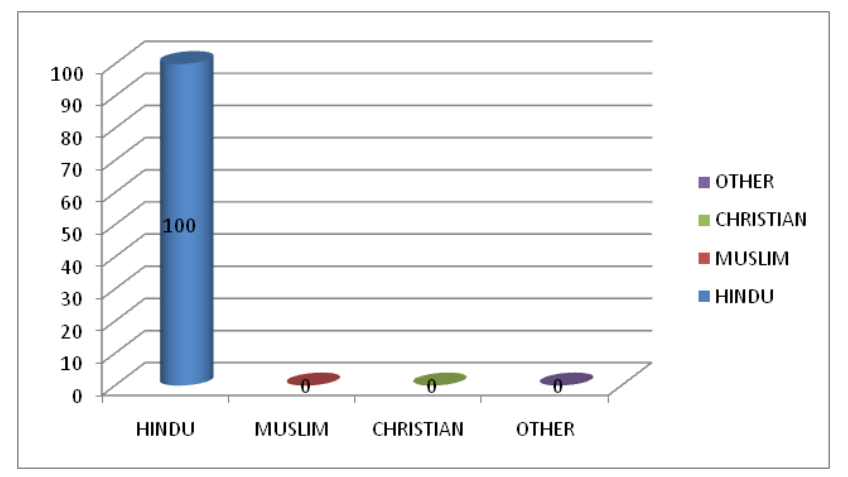

Graph 4 The above table revels that, $0(0 \%)$ of the respondent were yes, $50(100 \%)$ and remaining of the respondent were No.

\section{Plan for data analysis}

The analysis of data involves the translation of information collected during the course of research project into an interpretable and manageable form. It involves the use of statistical procedure to give an organisational meaning of the data. The descriptive and the inferential statistics will be used for data analysis. Table 2 The various categories for analysis numerical data based on the objective on the study on given below.

i. Demographic data will be analysed using frequency and percentage. ${ }^{17}$ 
ii. Knowledge of the students will be analysed by computing frequency, percentage, mean, median, mean percentage and standard deviation.

Table 2 Knowledge score categorized

\begin{tabular}{lll}
\hline Marks [Gread] & Frequency & Percentage \\
\hline 0-6 (Poor) & 0 & 0 \\
7-14 (Average) & 19 & 38 \\
14-20 (Good) & 31 & 62 \\
Total & 50 & 100 \\
\hline
\end{tabular}

\section{Section II: knowledge questionnaires}

The findings clearly show that there is no one student had poor knowledge regarding CPR among the $1^{\text {st }}$ year RGNM students. Graph 5 There is $38 \%$ of adequate knowledge regarding CPR and the majority of $62 \%$ students having good knowledge about cardiopulmonary resuscitation (CPR).

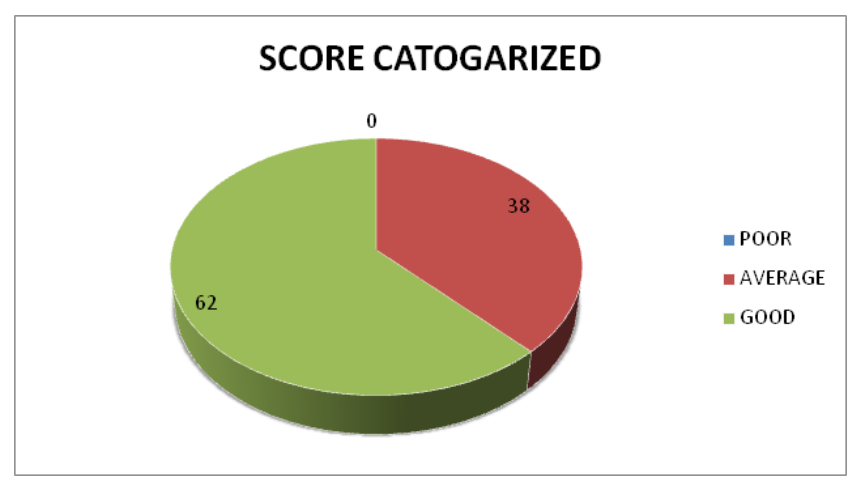

Graph 5 Graphical representations of the knowledge questionnaires.

\section{Conclusion}

The findings indicate that the GNM students required more knowledge and skill regarding CPR to practice effectively to save life of a victim. Even though majority of the GNM (diploma nursing students) had good knowledge but still perfection is required to practice it whenever needed in emergency.

\section{Ethical clearance}

Permission got from principal SND College of Nursing.

\section{Funding}

Self

\section{Acknowledgements}

We would like to thank our beloved management Mr. Narendraji Darade, Mr. Kishoreji Darade, Principal Prof. Neethi Selvam, Mr. Prashant H.J and our entire faculty.

\section{Conflict of interest}

The author declares that there is no conflict of interest.

\section{References}

1. Brunner and Siddhartha's, Text book of Canadian. Medical - Surgical Nursing. 2009.

2. Basavantappa BT, Text book of Medical. Surgical Nursing, 2003.

3. www.wikipedia.com/cardiopulmonaryresuscitation

4. Yakel ME, Hear Lung Organization.1989;18(5):520-525.

5. Australian journal of advance nursing. 2009; 26:58.

6. American Heart Association, CPR Guidelines 2010.

7. http://www.co.fremont.id.us/departments/ems/index.htm

8. Nursing Journal of Chinos People Liberation Army 2011 MA Su-fang1, PENG You-ging2, ZHANF Mei-ying3, ZHANF Xiao-li1.

9. Roosa JR, Vadeboncoeur TF, Dommer PB, et al. CPR variability during ground ambulance transport of patients in cardiac arrest. Resuscitation. 2013;84(5):592c595.

10. Sita Parajulee, Valarmathi Selvaraj. Knowledge of Nurses towards Cardiopulmonary Resuscitation in a Tertiary Care Teaching Hospital in Nepal. JCDR. 2011;5(8):1585-1588.

11. Mark L. DeBard. Cardiopulmonary resuscitation: Analysis of six years experience and review of the literature. Annals of Emergency Medicine. 1981;10(8):408-416.

12. JuhaNyman, MarjaSihvonen. Cardiopulmonary resuscitation skills in nurses and nursing students. Resuscitation. 2000;47(2):179-184.

13. Nyman J, Shivonen M. Helsinki Polytechnic. Tukholmankatu. 2000;47(2):179-184.

14. Shanta Chandrasekaran, Sathish Kumar. Awareness of basic life support among medical, dental, nursing students and doctors. Indian Journal of Anesthesia. 2010;54(2):121-126.

15. Masui. "Asahikawa Medical College Hospital”. 2003;52(4):427-430.

16. University of Western Sydney Library.

17. Brunner and Siddhartha's, Text book of Canadian. Medical - Surgical Nursing. 2009. 